\title{
Brucelosis: metodologías diagnósticas e interpretación de resultados
}

\author{
Olga C. Marlño-Jannaut. Ph.D \\ ICA - CEISA, Laboratorio de diagnóstico Bogotá DC. Colombia
}

La brucelosis es una zoonosis que afecta principalmente al ganado bovino, ovino, caprino y porcino. En los animales, la infección causa abortos, aumento de la mortalidad perinatal e infertilidad existiendo diversas vías de transmisión intra e interespecíficas. El hombre contrae la enfermedad por contacto directo, durante el manejo de animales, faenamiento o por ingestión de productos lácteos frescos contaminados.

La repercusión socioeconómica de la brucelosis es grande en los países que no la han erradicado. En Colombia, las pérdidas económicas en bovinos no han sido calculadas en toda su extensión, sin embargo, evaluaciones realizadas hacia 1993 sugieren valores hasta de 27.000 millones de pesos al año.

El control y la erradicación de la brucelosis requiere por lo menos de cuatro medidas diferentes y coordinadas a saber: vacunación, diagnóstico, remoción de reactores y vigilancia epidemiológica. Si una de estas acciones falla o se cumple parcialmente, la enfermedad permanece como una constante o emergente pesadilla. Se dispone actualmente de herramientas que permiten cumplir la primera con la aplicación reglamentaria de vacunación, cepa 19 o R651 (Resolución 00286 Febrero 16 de 1999) y para la segunda se ha demostrado la utilidad de pruebas serológicas de alta sensibilidad y especificidad para la determinación de la situación real, el establecimiento de hatos y áreas libres de la enfermedad y la disminución del riesgo de la enfermedad para el humano. Las últimas medidas se encuentran reglamentadas apropiadamente, pero comprenden aspectos económicos y de educación sanitaria que los han hecho difíciles de llevar a la práctica. En el país las autoridades gubernamentales encargadas de la sanidad animal representadas por el ICA han presentado para su ejecución el Proyecto de Prevención y Control de la Brucellosis Bovina con el objeto de disminuir progresivamente la frecuencia de la presentación de la enfermedad en el territorio nacional hasta alcanzar las condiciones óptimas para su erradicación.

Brucella es un parásito intracelular facultativo de replicación intracelular y por consiguiente la respuesta inmune de tipo celular es crucial para su eliminación o para proteger el húesped de la infección. Sin embargo, la infección genera la producción de anticuerpos en el animal, los cuales son empleados en el diagnóstico, aun cuando no protegen contra la enfermedad. Luego de la entrada en el organismo, la bacteria invade primero los ganglios linfáticos regionales, si se vence esta barrera del

Correspondencia: Olga C. Mariño-Jannaut. Ph.D ICA-CEISA Fax: 3686826 Avenida El dorado \# 42-42 Bogotá D.C.

E-mail:ocmarino@andinet.com 
sistema inmunitario, se propaga por la vía linfática o por la sangre, hacia el hígado, el bazo y el tracto reproductor. Brucella se aloja paradójicamente en la células fagocíticas, cuya función estriba en la eliminación de agentes extraños al organismo. Se cree que el principal mecanismo de eliminación de la Brucella, es la activación de macrófagos al igual que su destrucción por linfocios T, Th1 (CD4), presentando antígenos de Brucella en asociación con moléculas de clase II del complejo mayor de histocompatibilidad. Asímismo, se cree que linfocitos T citotóxicos CD8+, median la destrucción de células infectadas a través de la interacción con moléculas clase I asociadas con los antígenos de Brucella, linfocitos que se diferencian por acción de interleucinas y otros factores. Se cree que el papel de los anticuerpos contra estructuras externas, cadena-O de sLPS, comprende la destrucción de microognismos de $B$. abortus susceptibles por activación de complemento, la aglutinación de organismos reduciendo unidades infecciosas y por último la opsonización eficiente permitiendo a los microorganismos invadir macrofagos no infectados.

Los microorganismos del género Brucella poseen una envoltura celular formada por una membrana externa, un espacio periplásmico que contiene peptidoglican y una membrana citoplasmática. La parte exterior de la membrana externa es la única región bacteriana en contacto con el medio y contiene fosfolípidos, proteínas y un lipopolisacárido (LPS), asimétricamente distribuidos. Por su localización en la superficie de la célula y su inmunogenicidad, el sLPS es el primer antígeno frente al cual aparecen anticuerpos ( $\operatorname{lgM}, \lg G)$, tanto en la infección como en la vacunación con cepa 19.

El diagnóstico inequívoco de la brucelosis es el directo, por cultivo a partir de leche o tejidos del animal e identificación del germen. Sin embargo, el aislamiento es difícil y laborioso, por lo que generalmente el diagnóstico se realiza por métodos indirectos de comprobación de la res- puesta inmune ante la infección (MacMillan, 1990). En el presente, se evalúa simultáneamente la funcionalidad de metodologías capaces de identificar secuencias de genoma específicas, PCA, para perfeccionar la capacidad detectora diagnóstica.

En la práctica, el diagnóstico de brucelosis se basa en la determinación de la presencia de anticuerpos en suero mediante pruebas de aglutinación rápida Rosa de Bengala, Fijación de Complemento, Elisa indirecta y Elisa competitiva, las cuales contribuyen a unificar criterios tendientes a lograr el control y finalmente la erradicación de la enfermedad. La comparación entre las diferentes técnicas ha sido realizada por varios investigadores con el fin de evaluar la utilidad de cada una de ellas en el diagnóstico de Brucelosis y se han realizado evaluaciones a nivel local sobre el comportamiento de las metodologías inmunoenzimáticas en leche.

Durante la vacunación con cepa 19, los anticuerpos lgM aparecen hacia el día 5, alcanzando su pico a los 13 días post-vacunación. Los anticuerpos $\operatorname{lgGl}$ aparecen un poco más tarde o simultáneamente con la lgM, llegando a valores máximos entre los 28 y 42 dias, momento en el cual se inicia su eliminación. Los mismos patrones generalmente se cumplen en la infección experimental con cepa virulenta y también en los casos crónicos de campo, excepto que la actividad de los anticuerpos lgM declina a valores bajos y la actividad residual permanece en $\lg G 1, \lg G 2$ e $\lg A$, los cuales se mantienen en títulos elevados.

También se ha establecido la presencia de respuesta humoral a las proteínas de membrana externa, la cual si bien no es comparable a la producida para los antígenos sacáridos, si ha despertado gran interés con respecto a las posibilidades diagnósticas que puedan tener en caso de la utilización de cepas vacunales rugosas como la RB-51.

En animales infectados, a medida que la 
infección progresa, las lgG alcanzan un nivel más alto y persisten por períodos más prolongados, debido a que la infección de campo al sobrepasar los mecanismos primarios de defensa del huésped producen una infección persistente y prolongada que induce el mantenimiento elevado de anticuerpos contra el sLPS, razón por la cual la persistencia de lgG se asocia con la presencia de infección. Sin embargo, en los animales vacunados en ocasiones repetidas se presenta también una infección persistente con la producción durante un tiempo prolongado de lgG. Situación que ocasiona una dificultad muy grande en la diferenciación de animales infectados y vacunados con cepa 19 por el aumento del título serológico, incrementándose aún más el problema cuando los animales se vacunan varias veces o cuando se presentan combinaciones de infección de campo y vacuna. En términos generales, se puede hacer una diferenciación entre ambas condiciones, siempre y cuando exista una sola vacunación y ésta haya sido realizada en la edad más temprana posible. Por el contrario, cuanto mayor sea la edad y más numerosas las exposiciones vacunales, la posibilidad de diferenciación desaparece.

Dada la facilidad que tienen los bovinos para transmitir los anticuerpos a sus crías a través del calostro y a que en el momento del parto se presenta una transferencia masiva y selectiva de anticuerpos a la leche, especialmente de clase lgG, se encuentra una proporción mayor de estas inmunoglobulinas con relación a los anticuerpos de tipo $\lg A$. Se puede entonces pensar que cuando en la hembra existen IgG debido a una infección persistente éstas son transferidas en cantidad considerable a la leche. Las lgM sin embargo, permanecen en la sangre sin ser transferidas. Además, la glándula mamaria puede producir inmunoglobulinas del tipo $G$ y $A$ como respuesta a una infección local.

En nuestro medio, el objetivo de las pruebas serológicas no es solo el de identificar los animales que estan infectados, sino también el diferenciar los animales que han sido vacunados y están sanos, de aquellos que habiendo sido vacunados o no, estén infectados. Esto debido a que la vacunación no protege al ciento por ciento de los animales.

La comparación entre las diferentes técnicas, ha sido realizada por diferentes investigadores con el fin de evaluar la utilidad de cada una de ellas en el diagnóstico de la brucelosis (Nicoletti, 1969; Stemshorn, 1983, Stermshorn y col., 1985; Mariño y col., 1990, 1992, 1998). Como requisito previo a la utilización de una nueva técnica en un programa de diagnóstico, se requiere que la sensibilidad y especificidad sea comparada con pruebas de referencia (Mariño y Cols, 1998). La especificidad de una técnica se define como la probabilidad de dar un resultado negativo cuando ésta es aplicada a un animal no infectado. Un alto nivel de especificidad garantiza que la técnica no clasifica incorrectamente animales no infectados, como positivos. La sensibilidad, es la probabilidad de dar un resultado positivo cuando la técnica se aplica a un animal infectado. Una prueba con alta sensibilidad previene que un número excesivo de animales infectados escapen a la determinación. La sensibilidad y especificidad de una técnica puede variar a medida que cambian las características de la población de animales, como es el caso de la vacunación a brucelosis, razón por la cual se requiere conocer estos dos factores tanto en una población vacunada como en una libre.

La simplicidad, aceptabilidad y seguridad son cualidades definidas como importantes en la eficiencia de las pruebas biológicas. Sin embargo, los conceptos de eficiencia diagnóstica, pueden ser confusos si se sugiere que la sensibilidad y la especificidad son características constantes de una prueba, estos dos parámetros, pueden variar dentro de la población y más aún cambiarán con la prevalencia a medida que avanza el control o la eliminación de la enfermedad. En general, es común emplear una pruebarápida, económica y de alta sensibilidad como prueba tamiz o de excrutinio masivo y utilizar 
una o más pruebas adicionales como confirmatorias de los animales positivos. En este caso, también es necesario conocer la sensibilidad y especificidad de las técnicas confirmatorias.

Las múltiples comparaciones de técnicas inmunoenzimáticas realizadas con respecto a las convencionales han demostrado la utilidad de la ELISA indirecta como prueba tamiz de elevada sensibilidad con respecto a la Rosa de Bengala y de la ELISA competitiva con respecto a la fijación de complemento como prueba confirmatoria y diferencial del estatus de infección o vacunación de los animales reactores positivos en la prueba indirecta (Nielsen, 1998), sugiriendose su aplicación para agilizar los programas de control y erradicación de la infección y para garantizar el comercio internacional.

\section{REFERENCIAS}

Alton, G.G., Jones, LM., Angus, R.D.. Verger, J.M. 1988. Techniques for the brucellosis laboratory. Institute National de la Recherche Agronomique. Paris. 190pp.

Mariño, O. C.; Rueda de C., O. E.; Sedano, L.; C. Ramírez. 1992. The use of ELISA to evaluate antibodies to Brucella abortus in naturally infected cattle. FAO/IAEA. In: Immunoassay and DNA probe techniques for the diagnosis of animal diseases in Developing countries. FAO/ IAEAISIDA. TECDOC-657.

Wright, P.F., Nilsson, E., Van Rooil, E.M.A., JEGGO, M.H. 1993. Standardisation and validation of enzymelinked immunosorbent assay techniques for the detection of antibody in infectious disease diagnosis, Rev. Sci. Tech. Off. Int. Epiz. 12:435-450.

Mariño, O.; Gallego, 1.; Sedano, L.; Rueda, E. Schurig, G. G. 1996. Evaluation of potencial vaccine Brucella abortus RB-51. Susceptibility and protection in guinea pigs. Networking in Brucellosis Research II. J. J. Frank Ed. The UNU Press Tokio. Proceedings of the UNU/BIOLAC Brucellosis Workshop UNUP 101 0:197-210.
Mariño, O. C.; Rueda, E.; D. Gall; K. Nielsen. 1997. Comparative evaluation of competitive ELISA test in Colombian cattle. Towards Livestock Disease Diagnosis and Control in the 21 Century. Proceedings Series (Poster). IAEA STI/PUB/1023.

Gall, D.: A. Colling; O.C. Mariño; E. Moreno; K. Nielsen; C Peraza; B. Pérez; C. Sanmartino. 1998. Enzyme immunoassay for the diagnosis of bovine brucellosis: Trial in Latin America. Clinical and Diagnostic Laboratory Immunology. Vol.5 No. 5:654-661.

Nielsen, K. 1998. Brucellosis: Development and success using ELISAs for diagnosis. In: Toward livestock diseases diagnosis and control in the 21st century. IAEA/FAO STI/PUB/1023. 35-45.

Yongqun H.; R. Vemulapalli; G Schurig. 1999. Developmet of cytotoxic lymphocytes able to destry Brucella-infected macrophages after vaccination with strain RB-51. CRWAD 80 Annual meeting. Proceedings. Chicago. III. USA. 